\title{
The housing first model (HFM) fidelity index: designing and testing a tool for measuring integrity of housing programs that serve active substance users
}

\author{
Dennis P Watson ${ }^{1 *}$, John Orwat ${ }^{2}$, Dana E Wagner ${ }^{3}$, Valery Shuman ${ }^{4}$ and Randi Tolliver ${ }^{4}$
}

\begin{abstract}
Background: The Housing First Model (HFM) is an approach to serving formerly homeless individuals with dually diagnosed mental health and substance use disorders regardless of their choice to use substances or engage in other risky behaviors. The model has been widely diffused across the United States since 2000 as a result of positive findings related to consumer outcomes. However, a lack of clear fidelity guidelines has resulted in inconsistent implementation. The research team and their community partner collaborated to develop a HFM Fidelity Index. We describe the instrument development process and present results from its initial testing.

Methods: The HFM Fidelity Index was developed in two stages: (1) a qualitative case study of four HFM organizations and (2) interviews with 14 HFM "users". Reliability and validity of the index were then tested through phone interviews with staff members of permanent housing programs. The final sample consisted of 51 programs (39 Housing First and 12 abstinence-based) across 35 states.

Results: The results provided evidence for the overall reliability and validity of the index.

Conclusions: The results demonstrate the index's ability to discriminate between housing programs that employ different service approaches. Regarding practice, the index offers a guide for organizations seeking to implement the HFM.
\end{abstract}

Keywords: (3-10): Housing, Fidelity, Implementation, Instrument development, Mixed methods, Harm reduction, Low-demand

\section{Background}

Substance abuse is often offered as an explanation for the difficulty homeless individuals have accessing and maintaining housing. While substance abuse likely contributes to housing instability in some way (e.g., potential difficulty managing money and paying rent or increased potential for interpersonal disputes), it is also important to recognize that structural-level barriers to stable permanent housing also exist. Chief among these barriers are the stated and unstated policies determining

\footnotetext{
* Correspondence: dpwatson@iupui.edu

'Department of Health Policy and Management, Indiana University, Richard M. Fairbanks School of Public Health, Indiana University-Purdue University Indianapolis, 714 N. Senate Ave, Indianapolis, IN 46202, USA

Full list of author information is available at the end of the article
}

who is eligible to access housing and the behaviors they must engage in to retain it [1]. Many policies guiding homeless services follow an abstinence-based approach requiring consumers to obtain sobriety (typically for 30-90 days) before they become eligible for housing. Likewise, individuals often must remain sober to keep their placement and/or advance to more independent levels of housing. This abstinence-based approach has been connected to problems such as higher consumer dissatisfaction and disengagement from services $[2,3]$.

Developed in response to problems such as these, the Housing First Model (HFM) places lower demands on consumers. It has become the driving force of policies aimed at ending chronic homelessness due to its success engaging "hard-to-serve" individuals [4-6]. Despite this, 
wide diffusion coupled with a lack of clear implementation guidelines has led to confusion as to the elements of the model necessary for replication [7-9]. We created the HFM Fidelity Index in an effort to address the gap between HFM policy and community practice. In this paper we present results related to the development and testing of the index.

\section{Description of the HFM and its diffusion}

The HFM was developed to serve individuals who are chronically homeless and who have been dually diagnosed with both a serious mental illness and a substance use disorder-a group that makes up anywhere from 10 to 20 percent of the total homeless population $[4,5,10]$. Pathways to Housing Inc. developed what is often credited as the first HFM program (then named the Consumer Preference Supported Housing Model) in the early 1990s. A key feature that distinguished the Pathways program from those following an abstinence-based approach was a lack of a sobriety requirement for admission to and retention of housing [11]. This lack of requirement is based in a harm reduction approach to services, which seeks to reduce the negative consequences related to substance abuse (and other high-risk behaviors) rather than eliminating substance use altogether $[12,13]$.

In addition to reduced substance use and abuse [14], some of the key outcomes differentiating HFM from abstinence-based programs are: fewer emergency room visits and hospitalizations [15]; higher perceived choice in services [16,17]; reduced involvement in criminal activity [18]; and higher housing retention rates [19,20]. The United States Interagency Council on Homelessness and the National Alliance to End Homelessness became advocates of the HFM after programs based on its demonstrated ability to retain consumers in housing (i.e., residential stability) $[4,6]$. These endorsements resulted in rapid, nation-wide diffusion of the model over the past 12 years, which is largely related to local-level policies focused on ending chronic homelessness through a Housing First approach. This approach largely entails redirecting monies from traditional shelter services toward the development of more permanent and supportive housing options, particularly those that operate using the HFM [21].

Despite the intent of these policies, previous research has demonstrated challenges related to implementation of the HFM. In one study, George et al. [7] found that some providers who had experience working in an abstinence-based environment had difficulties understanding HFM policies and practices, particularly those related to harm reduction. Misunderstandings such as these can lead to modifications during the implementation process that can severely weaken a program model $[22,23]$. Indeed, Pathways staff have even begun to differentiate their program from other HFM programs as differences in implementation (and possible issues associated with it) have been recognized: "we [Pathways staff] refer to it as the Pathways Housing First (PHF) program to distinguish it from other programs that also identify with the Housing First approach" [24] (p. 4).

Seeking to better understand HFM implementation in the community, the U.S. Department of Housing and Urban Development (HUD) commissioned an exploratory study that sought to understand the characteristics of HFM programs [9]. The program characteristics the authors of this study point to include: (a) direct placement of consumers into permanent housing; (b) availability of supportive services without requirement to participate; (c) use of assertive outreach to engage reluctant consumers; (d) approaches to ensure relapse does not result in eviction; and (e) continuation of housing and case management services if clients leave for short time periods. This study was an important first step in understanding how the HFM has translated into community practice.

\section{Fidelity}

Many factors can negatively affect an organization's decision to adopt a specific evidence-based model for substance abuse intervention and its resulting implementation (e.g., size, resources, staff attitudes and education, local laws and policies) [25,26]. In this light, it is necessary for researchers, policy makers, and practitioners to have tools at their disposal for measuring the extent to which a model has been implemented in practice. This helps reduce the chance that outcomes, positive or negative, will be misappropriated to a model never fully implemented in practice, a phenomenon referred to as a Type III error in the implementation literature [27]. Fidelity measures are just such a tool, and research has established there is a positive association between fidelity and program outcomes [22,23]. Despite this, intervention effectiveness studies rarely pay attention to fidelity [28].

Fidelity has traditionally been conceptualized as strict adherence to the model as it was tested under scientific conditions [22]. However, a number of scholars have argued it is necessary for organizations to make adaptations to a model based on their particular circumstances $[22,29,30]$. For example, through a case study of a multisite fidelity assessment of individual projects providing substance abuse services, Orwin found that all 14 sites deviated to some degree from the implementation plan due to unique difficulties they each faced [31]. Similarly, Neumiller et al. found that challenges to implementing the Assertive Community Treatment (ACT) service model for people who were homeless with co-occurring disorders-a key ingredient of PHF programs [24] - resulted in modifications to the model in all 9 programs involved in their study, and that these 
modifications were made with knowledge that they would result in lower fidelity to the original model [32]. Matejkowski and Draine found that ACT services were often adapted among a sample of HFM programs due to the model's focus on consumer choice in services [33]. For those who see adaptation as beneficial, program implementation is a complex process for which organizational context is an important factor, and modifications are allowable as long as the program delivers the "critical elements" that distinguish it from other models [22,34]. Identification of the critical elements provides a guide as to what can be modified during adaptation to local conditions [25,35].

While adaptations to the HFM might be appropriate and necessary in many instances, modifications that are in direct conflict with its basic underlying philosophythose that are abstinence-based rather than harm reduction-based-are not appropriate. Therefore, development of a HFM fidelity instrument is critical to the successful implementation and measurement of the model. The focus of this paper is the development and testing of a HFM fidelity index.

\section{Methods}

The study was carried out between August 2009 and August 2011. Researchers collaborated with staff at Heartland Health Outreach (referred to as Heartland hereafter). Heartland is a large social service organization that operates HFM programming, and also offers training and technical assistance to agencies seeking to implement HFM-based policies and practices. Researchers and Heartland staff worked in collaboration to ensure knowledge gained from the study would be appropriate for dissemination through both the academic and practice communities [36]. Procedures were approved by the Institutional Review Boards at Loyola University Chicago and Heartland Alliance.

\section{Development of the fidelity index}

No fidelity instrument had been created at the time we started development of the HFM Fidelity Index. Recognizing wide diffusion of the HFM without fidelity guidelines had resulted in variations from the original model, we took a bottom-up approach to the development of the index that sought to identify and operationalize the critical elements of the HFM that differentiate it from the abstinence-based approach $[37,38]$. What this means is that we sought to understand the policies and practices of programs as they existed in a wide variety of contexts in an effort to identify those most central to the HFM's success. We developed an initial index through two phases. We describe these phases and the initial instrument before discussing its final testing.

\section{Phase 1}

We provide a brief overview of Phase 1 in this section (methods and results for this phase are described in greater detail in another article [39]). Phase 1 was carried out by the first author, who employed a qualitative case study methodology with four local housing agencies [40]. Purposeful sampling techniques were used to select programs that were (a) strong examples of the HFM and (b) different enough in relation to program characteristics such as consumer capacity, population served, number of years operating a HFM, and housing type (single-site or multiple-site) to better assure similarities in themes would be related to the HFM rather than the organizational context [41]. Data were collected from 4 administrative interviews, 4 consumer focus groups (24 total participants), 3 staff focus groups (18 total participants), 21 consumer interviews, and 16 staff interviews. Staff received a $\$ 5$ coffee shop card and consumers received a $\$ 30$ grocery store card for their participation (consumers received a larger amount because staff completed the interviews during their work hours, and were therefore being compensated by their employers). Data collection and analysis were overlapping so incremental learning could guide collection efforts at subsequent levels [40]. Themes were identified both within and across cases as they related to the research questions. Emerging themes were discussed with administration at each agency and local housing experts, a qualitative approach to ensuring rigor and validity [41].

This process resulted in the identification of 6 broad elements of the HFM that were shared by the four organizations. (1) Each of the programs had low-threshold admission policy (LTAP) designed to place as few requirements as possible on potential consumers for program entry. Staff discussed the LTAP as the primary feature of their program that made it, and other Housing

\section{Table 1 Location of phase 2 participants}

\begin{tabular}{ll}
\hline City & Number of programs selected \\
\hline 1. Columbus & 2 \\
\hline 2. Dallas & 1 \\
\hline 3. Denver & 1 \\
\hline 4. Detroit & 1 \\
\hline 5. Houston & 1 \\
\hline 6. Indianapolis & 1 \\
\hline 7. Los Angeles & 1 \\
\hline 8. Minneapolis & 2 \\
\hline 9. New York & 1 \\
\hline 10. Philadelphia & 1 \\
\hline 11. San Francisco & 1 \\
\hline 12. Seattle & 1 \\
\hline Total & 14 \\
\hline
\end{tabular}


Table 2 Means and standard deviations for specific items inquired about in phase 2 "user" interviews

Assertive community outreach directly to:

\begin{tabular}{llll}
\hline 1. & $\cdot$ Potential consumers & 3.50 & 0.65 \\
\hline 2. & $\cdot$ Hospitals & 2.57 & 0.94 \\
\hline 3. & $\cdot$ Shelters & 3.64 & 0.63 \\
\hline 4. & $\cdot$ Interim housing programs & 2.07 & 1.07 \\
\hline 5. & $\cdot$ Government agencies & 2.43 & 0.76 \\
\hline 6. & Specific staff dedicated to outreach & 3.43 & 1.16 \\
\hline & Programs mainly target services towards: & 3.23 & 1.24 \\
\hline 7. & $\cdot$ Adults & 2.86 & 1.23 \\
\hline 8. & $\cdot$ Single individuals not attached to a family unit & 3.79 & 0.60 \\
\hline 9. & $\cdot$ Those who are chronically homeless & 3.79 & 0.43 \\
\hline 10. & $\cdot$ Those who have serious and persistent mental illness & 3.29 & 0.91 \\
\hline 11. & $\cdot$ Those who have a substance abuse disorder & 3.14 & 0.86 \\
\hline 12. & $\cdot$ Those who are actively using substances & 3.29 & 1.14 \\
\hline 13. & $\cdot$ Those who demonstrate a desire to move towards abstinence & 1.79 & 1.25 \\
\hline 14. & $\cdot$ Those who do not have a prior felony conviction & 1.21 & 1.25 \\
\hline 15. & $\cdot$ Those who have good credit and/or no convictions & \\
\hline
\end{tabular}

New consumers are assessed for:

\begin{tabular}{llll}
\hline 16. & $\cdot$ Housing readiness & 1.86 & 1.29 \\
\hline 17. & $\cdot$ Substance use & 2.71 & 1.07 \\
\hline 18. & $\cdot$ Mental health status & 2.93 & 0.92 \\
\hline 19. & $\cdot$ Physical health & 2.71 & 0.83 \\
\hline 20. & $\cdot$ Financial stability & 1.14 & 1.29 \\
\hline 21. & $\cdot$ Benefits and entitlements & 2.43 & 1.58 \\
\hline 22. & $\cdot$ New consumers submit to urinalysis & 0.36 & 0.84
\end{tabular}

Consumers admitted on:

23. 1. First come, first serve basis $1.92 \quad 1.19$

\begin{tabular}{llll}
24. & 2. Assessed need/vulnerability & 0.75 \\
\hline
\end{tabular}

25. Consumers to have benefits upon admission 1.21

26. Consumers to have insurance upon admission (i.e., Medicaid, Medicare) 1.08

27. Consumers to agree to money management as a precondition for admission 1.36

28. Consumers agree to representative payee ship 1.29

29. Educate incoming consumers on the principles of Housing First 3.14

30. Housing available in multiple neighborhoods or community areas 3.14

31. Allow consumers to change housing location once housed $\quad 1.18$

32. Temporary housing available to consumers while waiting for permanent placement $3.07 \quad 1.07$

\begin{tabular}{lll}
\hline 33. & Private landlords for housing sites & 0.89 \\
\hline 34. & Staf dedicated to locating housing stock
\end{tabular}

\begin{tabular}{llll}
\hline 34. & Staff dedicated to locating housing stock & 0.87 \\
\hline 35. & Staff dedicated to bulding relationships with propety managers & 3.38
\end{tabular}

35. $\quad$ Staff dedicated to building relationships with property managers 3.620 .65

36. Consumers do not share living spaces such as bedrooms, living rooms, bathrooms, or kitchens 2.71

\begin{tabular}{llll}
\hline & Housing property management to: & & \\
\hline 37 & - Allow consumers to use alcohol in unit & 2.85 & 1.52 \\
\hline 38. & - Allow consumers to use alcohol away from property & 3.57 & 0.76 \\
\hline 39. & - Allow consumers to use illegal drugs in unit & 1.85 & 1.77 \\
\hline 40. & - Allow consumers to use illegal drugs away from property & 2.92 & 1.55 \\
\hline
\end{tabular}


Table 2 Means and standard deviations for specific items inquired about in phase 2 "user" interviews (Continued)

\begin{tabular}{|c|c|c|c|}
\hline 41. & - Allow consumers to be intoxicated on housing property & 3.00 & 1.04 \\
\hline 42. & - Prohibit consumer use of any substances in unit & 0.71 & 1.20 \\
\hline 43. & - Prohibit consumer use of any substances at any time, in or away from unit & 0.43 & 0.76 \\
\hline 44. & Housing does not have time limits other than those defined by the standard lease/occupancy agreement & 3.71 & 0.50 \\
\hline 45. & Housing lease is not tied to any type of service agreements & 2.86 & 1.23 \\
\hline 46. & All consumers have representative payees & 0.93 & 0.10 \\
\hline 47. & Consumer has a representative payee when has trouble managing money & 2.71 & 0.99 \\
\hline 48. & Emergency funds available to assist consumers in need & 3.14 & 0.86 \\
\hline 49. & Consumer as the lease holder & 2.79 & 1.22 \\
\hline \multirow[t]{2}{*}{50.} & Agency as the lease holder & 1.36 & 1.34 \\
\hline & Require regular housing inspection for: & & \\
\hline 51. & - Cleanliness & 2.93 & 0.92 \\
\hline 52. & - Contraband & 0.86 & 1.17 \\
\hline 53. & Consumers participate in regular urinalysis to detect substance use & 0.21 & 0.58 \\
\hline 54. & Directly place consumers into permanent housing situation (rather than interim or safe haven) & 3.07 & 1.14 \\
\hline 55. & Allow consumer choice in housing location & 2.93 & 0.92 \\
\hline 56. & Keep active drug and alcohol users separately housing from non-users & 1.21 & 1.12 \\
\hline 57. & Consumers to be assigned case managers & 4.00 & 0.00 \\
\hline 58. & Consumers to have regular contact with a case manager as a condition of housing & 1.93 & 1.54 \\
\hline 59. & Case manager contact occurs in-person & 3.50 & 0.67 \\
\hline \multirow[t]{2}{*}{60.} & Reduce the number of face-to-face meeting with a case manager as a consumer demonstrates a growing level of stability & 2.33 & 1.51 \\
\hline & Consumers to be able to define: & & \\
\hline 61. & - Case manager meeting agenda & 2.79 & 0.80 \\
\hline 62. & - Case manager meeting time, within reason & 2.71 & 0.61 \\
\hline 63. & - Case manager meeting location, within reason & 2.43 & 1.16 \\
\hline 64. & Have an ACT Team & 2.79 & 1.25 \\
\hline 65. & Intensive case management services & 3.00 & 0.96 \\
\hline 66. & Consumer chooses level of engagement in services & 3.21 & 0.70 \\
\hline 67. & Supportive services located on housing site & 2.23 & 1.36 \\
\hline 68. & Consumers allowed to refuse supportive services & 2.79 & 1.05 \\
\hline \multirow[t]{2}{*}{69.} & Staff utilize assertive engagement with consumers to make services attractive & 3.64 & 0.50 \\
\hline & Important that consumers with mental health issues: & & \\
\hline 70. & - See a mental health practitioner & 2.79 & 1.12 \\
\hline \multirow[t]{2}{*}{71.} & - Are compliant with psychiatric medication & 2.36 & 0.84 \\
\hline & Consumers with physical health issues: & & \\
\hline 72. & - See a health care practitioner & 3.07 & 0.62 \\
\hline 73. & - Are compliant with their medication prescribed for physical health problems & 2.57 & 0.94 \\
\hline 74. & Consumer choose their own goals & 3.79 & 0.43 \\
\hline 75. & Low-demand approach to serving consumers & 3.67 & 0.65 \\
\hline 76. & Stage-based/stage-wise substance abuse treatment & 2.38 & 0.96 \\
\hline 77. & Harm Reduction approach to serving consumers & 3.57 & 0.65 \\
\hline 78. & Educate consumers about harm reduction & 3.15 & 0.99 \\
\hline \multirow[t]{2}{*}{79.} & Assess consumers for discharge readiness & 3.08 & 0.95 \\
\hline & Terminate housing services based on: & & \\
\hline 80. & - Excessive pedestrian traffic in and out of unit & 1.21 & 0.80 \\
\hline 81. & - Having people stay in unit who are not on the lease & 2.00 & 1.41 \\
\hline
\end{tabular}


Table 2 Means and standard deviations for specific items inquired about in phase 2 "user" interviews (Continued)

\begin{tabular}{|c|c|c|c|}
\hline 82. & - Keeping the unit in an unclean, hazardous state & 2.43 & 1.28 \\
\hline 83. & - Excessive noise & 1.79 & 1.18 \\
\hline 84. & - Threats of violence & 3.14 & 0.95 \\
\hline 85. & • Physical violence & 3.79 & 0.43 \\
\hline 86. & - Relapse & 0.14 & 0.36 \\
\hline 87. & - Alcohol use in room & 0.36 & 0.93 \\
\hline 88. & - Illegal substances in room & 1.50 & 1.65 \\
\hline 89. & - Any illegal activity in the room besides use of illegal substances & 2.31 & 1.44 \\
\hline 90. & - Nonpayment of rent & 2.29 & 1.33 \\
\hline 91. & Have formal eviction prevention protocol & 3.64 & 0.84 \\
\hline 92. & Continue providing services if housing is lost & 3.08 & 1.32 \\
\hline 93. & Work with consumers to prevent homelessness in preparation for eviction from housing & 3.86 & 0.36 \\
\hline 94. & Work with consumers to locate new housing if evicted & 3.57 & 0.65 \\
\hline 95. & Have a staff member dedicated to eviction and/or homelessness prevention & 2.07 & 1.90 \\
\hline 96. & Eviction and/or homeless prevention specialist is full-time & 2.30 & 1.70 \\
\hline 97. & Follow-up with consumers after voluntary discharge from housing/services & 2.71 & 1.14 \\
\hline 98. & Hold housing for consumers if they leave for short periods & 3.64 & 0.63 \\
\hline 99. & Continue case management services while housing is being held & 3.31 & 0.63 \\
\hline 100. & Minimum education qualifications for case managers & 3.00 & 0.88 \\
\hline 101. & Have an ethnically and culturally diverse staff & 3.86 & 0.36 \\
\hline \multirow[t]{2}{*}{102.} & Have formal protocol for hiring ethnically and culturally diverse staff & 3.07 & 1.07 \\
\hline & Have the following types of professionals at agency: & & \\
\hline 103. & - Psychiatrist or psychiatric nurse practitioner & 3.29 & 0.73 \\
\hline 104. & - Licensed mental health professional (e.g., social worker, psychologists, therapist, or counselor) & 3.00 & 1.04 \\
\hline 105. & - Certified substance abuse counselor & 2.36 & 1.22 \\
\hline 106. & - Vocational rehabilitation specialist & 2.36 & 0.84 \\
\hline 107. & - Medical doctor, nurse practitioner, or physician's assistant & 2.57 & 1.16 \\
\hline 108. & - Nurse & 2.57 & 1.02 \\
\hline 109. & - Peer counselors & 2.86 & 1.23 \\
\hline 110. & $24 / 7$ availability of at least one staff member & 3.36 & 1.01 \\
\hline 111. & Case managers are accessible (via phone) outside of normal working hours & 2.07 & 1.27 \\
\hline 112. & Case manager offices located in separate location from housing & 1.54 & 1.61 \\
\hline 113. & $\begin{array}{l}\text { Separate program staff who work with property management to enforce rules and regulations of housing if case manager } \\
\text { offices are onsite }\end{array}$ & 3.00 & 1.00 \\
\hline 114. & Allow staff to have flexible working schedules & 2.93 & 0.83 \\
\hline \multirow[t]{2}{*}{115.} & Staff meet regularly with a supervisor & 3.64 & 0.50 \\
\hline & Important for staff to be trained in: & & \\
\hline 116. & • Motivational interviewing & 3.57 & 0.65 \\
\hline 117. & - Crisis intervention & 3.86 & 0.36 \\
\hline 118. & - Harm reduction & 3.64 & 0.63 \\
\hline 119. & • 12-step model & 1.93 & 0.10 \\
\hline 120. & - Stages-of-change treatment & 2.93 & 0.83 \\
\hline 121. & - Cultural sensitivity & 3.71 & 0.50 \\
\hline 122. & - Other & $\mathrm{n} / \mathrm{a}$ & $\mathrm{n} / \mathrm{a}$ \\
\hline 123. & - Interdisciplinary team meetings & 3.57 & 0.51 \\
\hline 124. & Program to engage in program evaluation or outcome measure activities & 3.71 & 0.50 \\
\hline
\end{tabular}


Table 2 Means and standard deviations for specific items inquired about in phase 2 "user" interviews (Continued)

\begin{tabular}{|c|c|c|c|}
\hline 125. & Involve consumers in program decision making & 3.21 & 0.80 \\
\hline \multicolumn{4}{|c|}{ Agency to be involved in Housing First policy discussions at: } \\
\hline 126. & - Local level & 3.77 & 0.44 \\
\hline 127. & - State level & 3.46 & 0.66 \\
\hline 128. & - National level & 3.15 & 1.14 \\
\hline 129. & Utilize housing retention score as an indicator of successful Housing First programming & 2.67 & 1.23 \\
\hline
\end{tabular}

First programs, unique from the abstinence-based programs with which they were familiar. (2) Harm reduction was considered the practice or "tool" used to keep consumers housed. Harm reduction strategies do not require consumers to be abstinent from alcohol and drug use-harm reduction focused policies and practices stood out as the most critical element for running a successful Housing First program in all four sites. (3) Eviction prevention refers to a form of case management intervention aimed to prevent consumers from losing housing in light of lease violations. Because eviction of a consumer was an example of a programmatic failure in all of the organizations, eviction prevention was necessary for helping to assure program success. (4) Reduced service participation requirements, compared to those found in abstinence-based housing, were demonstrated to be important. Interview and focus group participants discussed how allowing consumer choice over their level of service participation was a powerful tool for facilitating positive change. (5) Separation between property management and case management roles and responsibilities was demonstrated to be important due to the effect on the consumer-staff relationship. While all programs had some separation between these two types of providers, it became increasingly difficult for consumers to develop trusting relationships with case managers as the lines between case management and property management roles blurred. (6) Strategies to inform and educate consumers about HFM policies and practices were important since their understandings of housing services were largely based on their histories with abstinence-based programs. Consumer-level data repeatedly demonstrated that education about the HFM was the mechanism that helped them attach meaning to the choices provided to them through the elements of harm reduction and reduced service requirements.

\section{Phase 2}

The goal of Phase 2 was to develop a more exhaustive list of elements with stronger operational definitions. To accomplish this goal, we carried out semi-structured phone interviews with "users" of the HFM (i.e., individuals who were Housing First program administrators or managers). The interview instrument for this stage was developed based on results from Phase 1 and a review of the existing HFM literature. Through this initial process, we developed a series of questions used to identify and create operational definitions for the elements included in the final index (a copy of this instrument can be obtained by contacting the first author). One hundred and twenty-nine of these questions asked users to determine how important they understood specific items to be to the HFM (on a scale from "0"/"not important" to "4"/"extremely important"). Additional questions inquired about such things as frequency, intensity, and duration related to specific items.

We recruited "users" from HFM programs located in the 25 largest urban areas in the country (where Housing First programs were likely to be) as identified by 2000 U.S. Census estimates. We identified 70 programs in these areas that operated using a HFM through an internet search and assistance from local government officials who oversaw the management of homeless service funds. Our goal was to recruit 20 users; however, we were only able to conduct 19 interviews due to time constraints. Five of these participants were removed from the sample after interviews were completed because we determined early in our analysis that they were employing a strict abstinence-based service approach that conflicted with the core philosophy of the HFM. Therefore, our final sample for Phase 2 comprised 14 HFM users from 12 cities (see Table 1). Participants received a $\$ 5$ coffee shop gift card, and their program was entered into a drawing to win a $\$ 500$ electronics store gift card.

In order to determine which items users understood to be most important to the HFM, we calculated descriptive statistics (mean and standard deviation) for each. We sorted all of the items by mean in ascending order so we could compare and discuss their relative importance (Table 2 displays the means and standard deviations for these items).

Through this process, we identified a total of 29 elements of the HFM, which we organized into 5 categories or overarching dimensions based on face validity. Our goal in this process was to create an instrument that would make conceptual sense to housing providers. Table 3 provides descriptions of each of the elements and their dimensions. 
Table 3 Dimensions and elements of the fidelity index and rational supporting inclusion in instrument ${ }^{a}$ Description

\begin{tabular}{|c|c|}
\hline Dimension I & Human resources-structure and composition: Refers to the composition and structure of the staffing. \\
\hline 1. Diverse staff & Program staff highly reflects the diversity within the consumer population. \\
\hline 2. Minimum education requirements & At least $25 \%$ of case managers have a Master's degree or higher. \\
\hline $\begin{array}{l}\text { 3. Harm reduction and crisis intervention } \\
\text { knowledge }\end{array}$ & Program provides or requires ongoing training in harm reduction and crisis intervention for staff [1 1 $]^{\mathrm{b}}$ \\
\hline 4. Staff availability & At least one staff member is available to consumers twenty-four hours a day, seven days a week [11]. ${ }^{b}$ \\
\hline 5. Clinical staffing & Program has psychiatric staff and mental health professional on staff or contract $[11,17]$. \\
\hline Dimension II & Program boundaries: Limits placed on who the program will serve and the responsibilities of key staff members. \\
\hline 6. Population served & $\begin{array}{l}\text { Program serves only chronically homeless and dually-diagnosed individuals, and it houses current drug users } \\
\text { [11]. }\end{array}$ \\
\hline 7.Consumer outreach & There is a designated staff member dedicated to outreach or an outreach department [11]. ${ }^{\mathrm{b}}$ \\
\hline 8. Case management responsibilities & Case management responsibilities are limited to case management. ${ }^{b}$ \\
\hline 9. Termination guidelines & $\begin{array}{l}\text { The program only terminates consumers who demonstrate violence, threats of violence, or excessive } \\
\text { non-payment of rent. }\end{array}$ \\
\hline 10. Termination policy enforcement & The service termination policy is consistently enforced. ${ }^{\text {b }}$ \\
\hline Dimension III & $\begin{array}{l}\text { Flexible policies: Policies and rules are written to appropriately serve consumers with greatest need/vulnerability } \\
\text { and to allow them maximum choice in terms of substance use and housing. }\end{array}$ \\
\hline 11. Flexible admissions policy & The program has formal protocol for admitting consumers with the greatest need/vulnerability [11]. \\
\hline 12. Flexible benefit/income policy & The possession of or eligibility for income benefits is not a prerequisite for housing. \\
\hline $\begin{array}{l}\text { 13. Consumer choice in housing } \\
\text { location }\end{array}$ & The program works with consumers to find desirable housing [11]. \\
\hline
\end{tabular}

14. Flexible housing

The program always attempts to relocate consumers when they are dissatisfied with their current housing placement [11].

15. Unit holding and continuation of The program holds housing for hospitalization and incarceration for more than 30 days and program continues case management to offer case management services while unit is unoccupied [9].

16. Flexible with missed rent payments The program is flexible with missed rent payments, but holds the consumer accountable. ${ }^{b}$

17. Flexible alcohol use policy The program allows alcohol use and housing allows alcohol in units [9]. ${ }^{b}$

18. Flexible drug use policy The program allows illicit drug use and housing allows illicit drug use in units [9]. ${ }^{b}$

19. Eviction prevention The program has a formal policy and protocol to work with consumers to prevent eviction and has a staff member dedicated to eviction prevention. ${ }^{b}$

\begin{tabular}{ll}
\hline 20. Consumer input into program & The program has formal and informal mechanisms for receiving and implementing consumer input. \\
\hline Dimension IV & Nature of social services: The structure, policies, and practices related to social services offered by the program.
\end{tabular} (there is some overlap with Dimension IV; however, this dimension refers specifically to social services)

21. Low-demand service approach Consumers are not required to engage in any services except for case management in order to receive/ continue receiving housing $[9,11]$.

22.

Harm reduction approach to service provision: Program uses a harm reduction approach and staff has a strong conceptual understanding $[9,11]$.

23. Regular in-person case management Consumers meet with their case managers 2-3 times a month on average, but program has a policy that more meetings frequent meetings occur in the first 1-6 months after admissions [11]

24. Small case loads
25. Ongoing consumer education
Dimension $\mathbf{V}$

Case managers have 10 or fewer consumers on their case load.

25. Ongoing consumer education Consumers receive ongoing education in Housing First and harm reduction policies and practices. ${ }^{b}$

Dimension V

Nature of housing and housing services: The structure of housing and housing services offered by the program and/or private landlords.

26. Structure of housing Housing is scattered-site in buildings operated by private landlords [11]. ${ }^{\mathrm{b}}$

27. Fast placement into permanent The program places consumers into housing in one week or less [11]. housing

28. Temporary housing placement Temporary housing placement does not last more than one month. ${ }^{b}$

29. Consumer is lease holder for housing $100 \%$ of consumers are the lease holders of their unit [11].

unit

${ }^{a}$ Citations reflect literature that guided rational for inclusion of element when Phase II findings were not conclusive and/or assisted in the final operationalization of the element.

${ }^{b}$ Phase I findings provided rational for inclusion when Phase II findings were not conclusive and/or assisted in the final operationalization of the element. 
Next we developed an index that would capture variations in each of the 29 elements. We created five ordinal anchors for each of the 29 elements for which a " 5 " described the strongest level of implementation of the element and " 1 " described the weakest. We created operational definitions for each of the anchors using the descriptive statistics calculated from the 129 items in the user interview as a guide. Generally, those items with a mean of 3 or higher were incorporated into the anchor describing the strongest level of implementation, and items with smaller means were incorporated into those anchors describing weaker levels. There were times when the descriptive statistics did not provide enough information for the construction of categories or conflicted with our understanding of the model. In these instances, we consulted the Phase 1 findings and the Housing First literature to guide the decision making process (see Table 3).
The anchors for the elements were complex due to their qualitative nature. Therefore, we developed a series of interview questions to ensure the information necessary to identify each element's correct anchor would be collected. To ensure face and content validity, researchers reviewed each of the elements, their dimensions, anchors, and interview questions with Heartland staff at multiple times throughout the instrument development process.

The instrument resulting from this two-phase process was designed to gather information about each of the 29 elements, background information about each program (e.g., type of housing offered, whether case managers were on-site or off-site, program self-identification as Housing First or abstinence-based, and how long the program had been in operation), and other data necessary to develop a housing retention score for each program (retention is the primary outcome of interest

Table 4 Means and standard deviations for individual elements by housing type

\begin{tabular}{|c|c|c|c|c|c|c|}
\hline \multirow[b]{2}{*}{ Element } & \multicolumn{2}{|c|}{$\mathrm{AB}(n=12)$} & \multicolumn{2}{|c|}{$\mathrm{HF} / \mathrm{AB}(n=18)$} & \multicolumn{2}{|c|}{ HF $(n=21)$} \\
\hline & Mean & SD & Mean & SD & Mean & SD \\
\hline 1. Diverse staff & 3.42 & 1.31 & 3.89 & 1.02 & 3.76 & 1.26 \\
\hline 2. Minimum education requirements & 3.92 & 1.51 & 4.17 & 1.54 & 4.67 & 0.97 \\
\hline 3. Harm reduction and crisis... & 2.75 & 1.71 & 3.61 & 1.69 & 3.48 & 1.72 \\
\hline 4. Staff availability & 4.67 & 0.78 & 4.50 & 1.04 & 3.71 & 1.49 \\
\hline 5. Clinical staffing & 2.83 & 1.34 & 3.39 & 1.09 & 3.57 & 1.33 \\
\hline 6. Population served & 2.58 & 1.00 & 2.61 & 1.04 & 2.67 & 0.91 \\
\hline 7. Consumer outreach & 2.50 & 1.31 & 2.67 & 1.24 & 2.90 & 1.48 \\
\hline 8. Case management responsibilities & 1.92 & 0.67 & 2.28 & 0.83 & 2.86 & 0.96 \\
\hline 9. Termination guidelines & 1.25 & 0.62 & 2.44 & 1.42 & 2.90 & 1.14 \\
\hline 10. Termination policy enforcement & 4.00 & 1.13 & 3.83 & 1.38 & 3.38 & 1.28 \\
\hline 11. Flexible admissions policy & 3.25 & 1.36 & 3.50 & 1.34 & 3.52 & 1.25 \\
\hline 12. Flexible benefit/income policy & 3.50 & 1.17 & 4.50 & 0.71 & 4.00 & 1.18 \\
\hline 13. Consumer choice in housing.. & 2.67 & 1.78 & 1.83 & 1.15 & 3.43 & 1.43 \\
\hline 14. Flexible housing relocation & 2.08 & 1.44 & 1.61 & 1.04 & 3.14 & 1.53 \\
\hline 15. Unit holding and continuation... & 4.08 & 1.31 & 3.50 & 1.65 & 4.14 & 1.28 \\
\hline 16. Flexible with missed rent payments & 3.25 & 1.42 & 3.00 & 1.33 & 3.81 & 1.33 \\
\hline 17. Flexible alcohol use policy & 1.67 & 1.37 & 3.61 & 1.75 & 4.62 & 0.80 \\
\hline 18. Flexible drug use policy & 1.08 & 0.29 & 1.83 & 1.34 & 3.10 & 1.04 \\
\hline 19. Eviction prevention & 3.00 & 1.04 & 2.83 & 0.79 & 3.52 & 0.87 \\
\hline 20. Consumer input into program & 4.08 & 1.24 & 4.17 & 1.10 & 4.14 & 1.06 \\
\hline 21. Low-demand service approach & 3.50 & 1.45 & 3.72 & 1.23 & 4.10 & 1.04 \\
\hline 22. Harm reduction approach... & 2.08 & 1.16 & 3.00 & 1.41 & 4.76 & 0.54 \\
\hline 23. Regular case management... & 2.42 & 1.73 & 2.06 & 1.66 & 2.62 & 1.75 \\
\hline 24. Small case load & 3.83 & 0.94 & 3.78 & 1.17 & 4.10 & 0.94 \\
\hline 25. Ongoing consumer education & 1.00 & 0.00 & 2.17 & 1.29 & 2.81 & 1.29 \\
\hline 26. Structure of housing & 3.42 & 1.51 & 2.72 & 1.71 & 4.48 & 1.21 \\
\hline 27. Fast placement into... & 2.83 & 1.53 & 3.33 & 1.78 & 2.57 & 1.54 \\
\hline 28. Temporary housing placement & 2.67 & 1.87 & 3.00 & 1.97 & 1.71 & 1.38 \\
\hline 29. Consumer is lease holder... & 3.67 & 1.97 & 4.83 & 0.51 & 3.57 & 1.89 \\
\hline
\end{tabular}


housing programs use to measure their success). Questions pertaining to each element were placed with its anchors in the survey. A copy of the final fidelity instrument is available from the first author.

\section{Testing of the instrument}

\section{Participating programs}

HFM and abstinence-based programs were recruited for participation. Abstinence-based programs are an ideal comparison group for determining discriminant validity because the HFM was developed as a solution to the problems associated with this type of housing [11]. To be included in the sample all programs had to (a) primarily serve individuals, rather than families, and (b) provide permanent housing. We randomly selected 140 permanent housing programs from a publicly available list of all 2009 U.S. Department of Housing and Urban Development (HUD) grant award recipients [42].
Research assistants called organizations and asked administrative officials whether their program followed a Housing First or abstinence-based model, as well as requesting their organization to participate in the study. We acquired consent for participation from each program's administrative office.

Our goal was to recruit a total of 40 HFM and 20 abstinence-based programs for participation in the study by randomly selecting programs from the list of 140 until our quota was met. We over-selected HFM programs in order to capture the diversity of programs that we understood to exist in practice based on previous research and the experience of Heartland staff. We completed 42 HFM and 13 abstinence-based interviews because of time restrictions related to our source of research funding. However, we removed one abstinencebased program and two HFM programs from the sample prior to analysis because we determined after the

Table 5 Item-total correlations for individual elements

\begin{tabular}{|c|c|c|}
\hline \multirow[b]{2}{*}{ Element } & \multicolumn{2}{|c|}{ All programs $(n=51)$} \\
\hline & Total fidelity score $=145$ & Total fidelity score $=120$ \\
\hline 1. Diverse staff & -.023 & --- \\
\hline 2. Minimum education requirements & 0.19 & 0.14 \\
\hline 3. Harm reduction and crisis... & 0.32 & 0.26 \\
\hline 4. Staff availability & -.01 & - \\
\hline 5. Clinical staffing & 0.33 & 0.33 \\
\hline 6. Population served & 0.27 & 0.27 \\
\hline 7. Consumer outreach & 0.15 & 0.16 \\
\hline 8. Case management responsibilities & -.030 & --- \\
\hline 9. Termination guidelines & 0.33 & 0.26 \\
\hline 10. Termination policy enforcement & -.022 & -- \\
\hline 11. Flexible admissions policy & 0.01 & 0.01 \\
\hline 12. Flexible benefit/income policy & 0.10 & 0.10 \\
\hline 13. Consumer choice in housing... & 0.35 & 0.45 \\
\hline 14. Flexible housing relocation & 0.45 & 0.55 \\
\hline 15. Unit holding and continuation.. & 0.30 & 0.31 \\
\hline 16. Flexible with missed rent payments & 0.31 & 0.35 \\
\hline 17. Flexible alcohol use policy & 0.57 & 0.56 \\
\hline 18. Flexible drug use policy & 0.50 & 0.54 \\
\hline 19. Eviction prevention & 0.22 & 0.27 \\
\hline 20. Consumer input into program & 0.33 & 0.31 \\
\hline 21. Low-demand service approach & 0.24 & 0.19 \\
\hline 22. Harm reduction approach... & 0.50 & 0.51 \\
\hline 23. Regular case management... & 0.03 & 0.08 \\
\hline 24. Small case load & 0.05 & 0.06 \\
\hline 25. Ongoing consumer education & 0.55 & 0.59 \\
\hline 26. Structure of housing & 0.41 & 0.50 \\
\hline 27. Fast placement into... & 0.06 & 0.08 \\
\hline 28. Temporary housing placement & 0.08 & 0.09 \\
\hline 29. Consumer is lease holder... & -.25 & --- \\
\hline
\end{tabular}


interviews that they did not meet the inclusion criteria despite the information administrators provided during the screening process (two did not primarily serve individuals and one did not provide permanent housing). We removed a fourth HFM program because significant parts of the interview were contradictory (the interviewee stated that staff were regularly trained in harm reduction, but also said the organization did not use harm reduction practices). The final sample consisted of 51 programs - 39 Housing First and 12 abstinence-based -from 35 states.

\section{Interview procedure}

Program case managers (or staff members who provided case management services) were invited to participate in fidelity interviews. Case managers were chosen, rather than administrators or managers, because they are in a key "front-line" position to understand (a) the program's policies and (b) the extent to which those policies are actually being implemented/practiced [43]. The interview took approximately 30-60 minutes to complete. Case managers received a $\$ 5$ coffee shop gift card for their participation and their program was entered into a drawing to win one $\$ 500$ or one of two $\$ 250$ electronics store gift cards.

\section{Analysis and results}

Subsequent to performing the fidelity interviews, we classified each program into one of three categories: (1) Abstinence-Based (AB; $n=12$ ), (2) Housing First with abstinence-based principles and/or practices (HF/AB; $n=18$ ), and (3) Housing First without abstinence-based principles and/or practices (HF; i.e., true Housing First programs; $n=21$ ). Our reason for dividing the programs that self-designated as "Housing First" into two categories was that a large number of them were employing abstinence-based policies and practices that conflicted with the core philosophy of the HFM. In order to create the groups, we identified all questions in the survey that indicated the presence of abstinence-based policies and/or practices (e.g., Does the program explicitly refuse to admit active substance users?; Does policy dictate that the program terminate consumers for active substance use?; Does your program require drug and/or alcohol abstinence of all consumers? Does your program work with substance abusing consumers using an abstinence-based approach?) and we moved a HF program to the HF/AB category if answers to any of these questions indicated the presence of abstinence-based policies and/or practices. Table 4 displays descriptive statistics for each of the 29 elements by each housing type.

Next, we summed the scores for each of the 29 elements to create an overall fidelity score. A program could score anywhere from 29 (lowest fidelity/least ideal implementation of the elements) to 145 (highest fidelity/ most ideal implementation of the elements).

We developed a number of questions to test the reliability and validity of the instrument. Each of these questions and the analysis approach we used to test them are listed below. All analyses were performed using SAS 9.3 statistical software. Because of the multiple steps involved in testing the instrument, we have combined a description of each analysis, its results, and some discussion in the sections that follow for the purpose of of providing greater clarity to the reader.

\section{Question 1: Do all 29 elements contribute to the reliability of the instrument}

To investigate the relationship between scores on individual elements and the total fidelity score, we calculated item-total correlations, which assist in determining which elements contribute to the index's reliability more than others. We expected that there would be variation in the relationship between each element and overall fidelity. We further expected that removing the negatively correlated items from the instrument would improve its internal consistency (i.e., raise Cronbach's alpha).

Table 5 displays correlation coefficients demonstrating the relationships between the overall fidelity score and each of the elements. The first column displays correlation coefficients related to all 29 of the original elements. A correlation of 0.30 or higher is considered desirable when interpreting item-total correlations [44]. However, we chose to only eliminate elements with

Table 6 Reliability of housing first dimensions before and after elimination of items with negative item-total correlations

\begin{tabular}{lcc}
\hline Dimension & $\begin{array}{c}\text { Cronbach's alpha } \\
\text { (with original 29 items) }\end{array}$ & $\begin{array}{c}\text { Cronbach's alpha } \\
\text { (with final 24 items) }\end{array}$ \\
\hline I. Human resources (structure and composition) & 0.39 & 0.39 \\
\hline II. Program boundaries & 0.17 & 0.05 \\
\hline III. Flexible policies & 0.66 & 0.67 \\
\hline IV. Nature of social services & 0.35 & 0.35 \\
\hline V. Nature of housing and housing services & 0.26 & 0.38 \\
\hline Overall & 0.68 & 0.75 \\
\hline
\end{tabular}




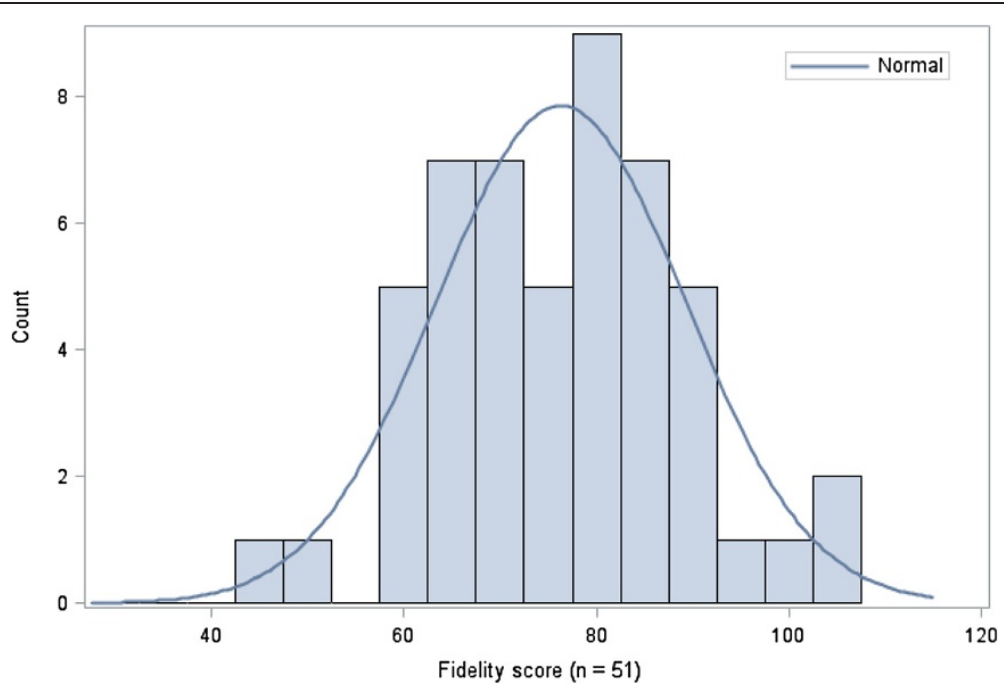

Figure 1 Histogram of adjusted fidelity scores (total possible score $=120$ ).

negative correlations because we consider the face validity established using the methods in the previous two phases to be a strength of the instrument.

The first column in Table 5 displays correlation coefficients related to all 29 of the original elements, 5 of which had negative relationships with the overall fidelity score. The second column in the table displays scores after removing the negatively correlated items and adjusting the total possible fidelity score to 120 .

Table 6 displays Cronbach's alpha coefficients for the overall index and each of the subdimensions before and after the removal of the negatively correlated ingredients. A score of 0.70 is the minimum desired for establishing internal consistency of an instrument [45]. As the table demonstrates, removal of the 5 negatively correlated items improved the internal consistency of the overall index. Only one of the subdimensions, flexible policies, was close to attaining a minimally desirable alpha coefficient in both analyses. This likely represents poor grouping of the elements given the internal consistency of the overall scale.

Subsequent analyses were conducted using items from the adjusted instrument. Figure 1 displays a histogram of the adjusted fidelity scores.

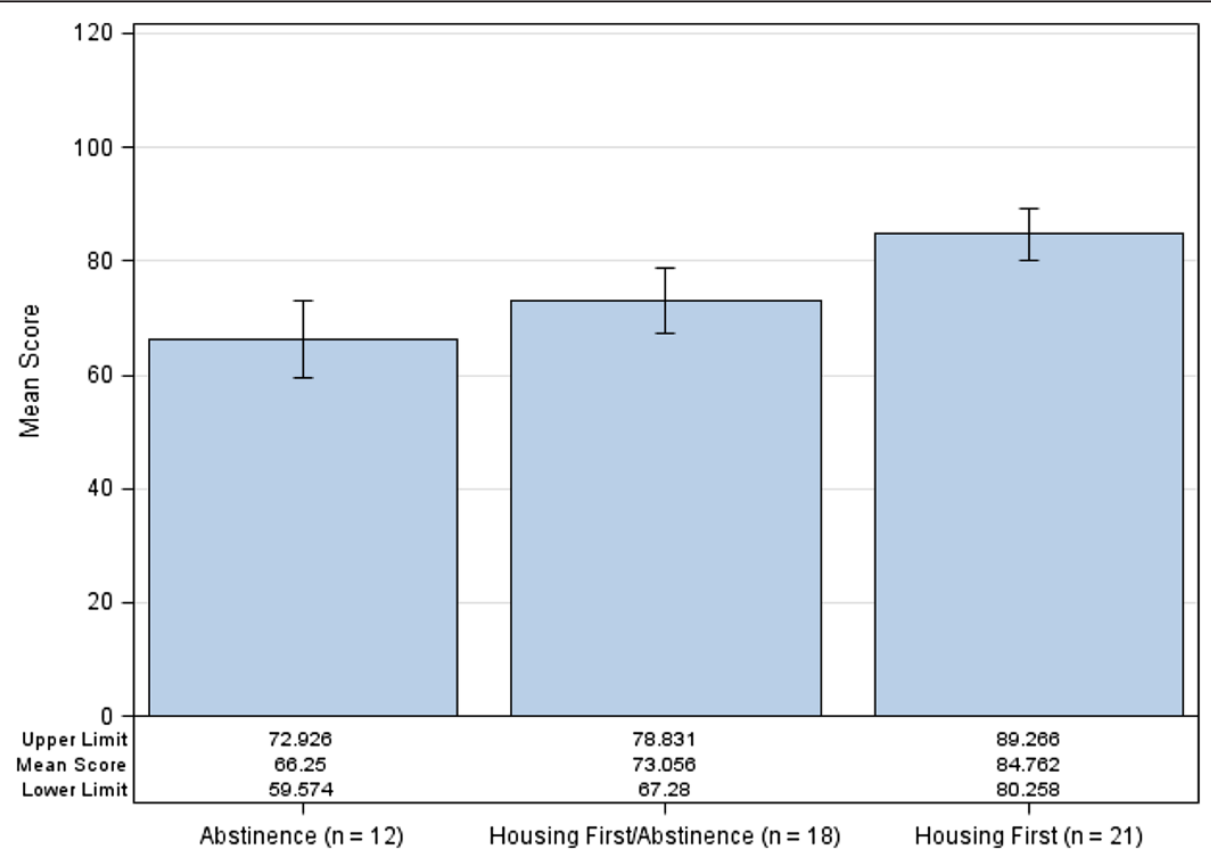

Figure 2 Mean fidelity scores with confidence limits by program type. 


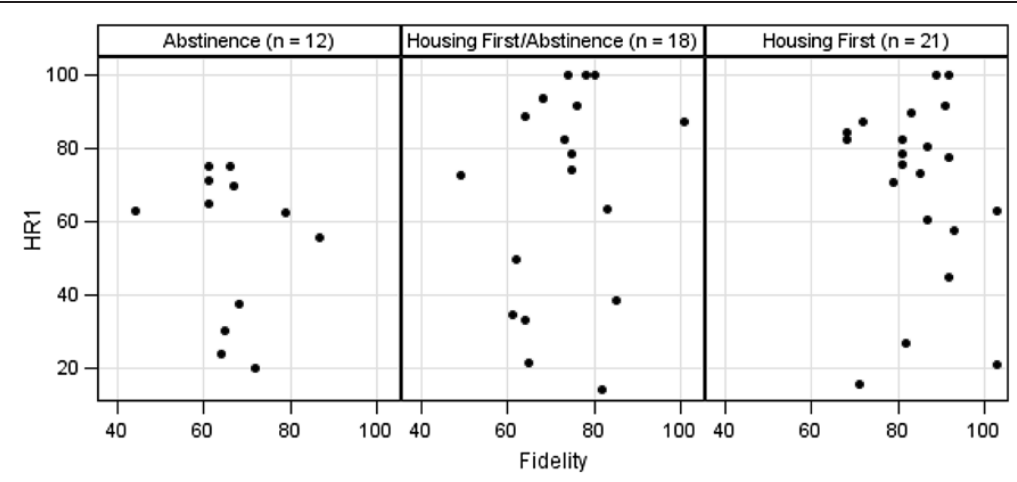

Figure 3 Scatterplot of First Housing Retention Score (HR1) and fidelity score by program type.

Question 2: Are there differences in mean fidelity scores between groups (i.e., Program Type)

Finding differences in mean fidelity scores between the three groups $(\mathrm{AB}, \mathrm{HF} / \mathrm{AB}, \mathrm{HF})$ is useful because it confirms that we formed the groups correctly and assists in establishing discriminant validity (i.e., fidelity scores should be higher among HF programs). We conducted a trend analysis in ANOVA with program type as the independent variable and fidelity score as the dependent variable [44]. We predicted that there would be a linear pattern where HF/AB programs would have higher mean fidelity than $A B$ programs and $\mathrm{HF}$ programs would have a higher mean fidelity than $\mathrm{HF} / \mathrm{AB}$ programs.

The mean fidelity score for the entire sample was 76.27 (SD=12.94). Figure 2 demonstrates the mean fidelity score for each of the program types with confidence limits. Results demonstrate that fidelity scores between the three groups were significantly different from each other in the predicted pattern, $\psi_{3}=18.51, t(48)=4.79$, $p<.0001$. HF programs had the highest mean fidelity score at $84.76(S D=9.89 ; n=21 ; 95 \%$ CI [59.57, 72.93]), followed by $\mathrm{HF} / \mathrm{AB}$ at $73.06(S D=11.61 ; n=18 ; 95 \%$ $\mathrm{CI}[67.28,78.83])$, and $\mathrm{AB}$ programs at $66.25(S D=10.51$; $n=12 ; 95 \%$ CI $[80.26,89.27])$.

Thus, we found a key strength of the instrument is that it is able to differentiate between program types.
This ability is rooted in the intensive qualitative work of the previous phases. It is through this work we were able to identify incompatibilities between the integration of abstinence-based policies and procedures and the underlying philosophy of the HFM. This provided the conceptual logic upon which we were able to recognize and create operational definitions for two different types of HFM programs ( $\mathrm{HF}$ and $\mathrm{HF} / \mathrm{AB}$ ), which may be useful for those seeking to implement and or measure the HFM at varying levels. This is particularly true for housing agencies that seek to develop HFM implementation plans while facing structural, policy, and/or philosophical barriers that might limit their ability to carry out harm reduction activities.

The relatively small mean difference between $A B$ and HF (18.51 points on a scale of 120) is notable. This is likely due to the fact that a number of the elements included in the instrument are aspects of quality housing programming that are not limited to the HFM. Future research warrants the investigation and possible removal of such elements from the index and/or weighting of those elements demonstrated to be more central to the model.

\section{Question 3: Is fidelity score related to housing retention}

In order to determine criterion validity, we calculated Spearman's rho correlations between total fidelity score and two measures of housing retention employed by

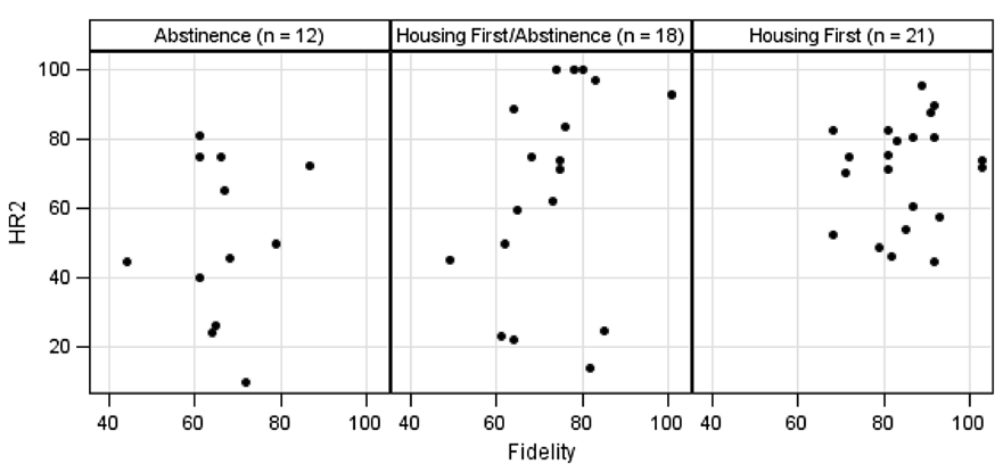

Figure 4 Scatterplot of Second Housing Retention Score (HR2) and fidelity score by program type. 
Heartland as part of its federal funding requirements. We calculated the first measure of housing retention (HR1) by dividing the total number of consumers who had been served by the program for a minimum of 12 months (including those who were served 12 months before entering the fiscal year and those who were served 12 months during the fiscal year regardless of whether they left the program during the fiscal year or not) by the total number of consumers served that fiscal year. We calculated the second measure (HR2) by dividing the total number of consumers who remained in the project from the first to the last day of the fiscal year (i.e., those who did not exit the project regardless of their length of stay) by the total number of consumers served during the year. We expected that fidelity would be positively associated with both types of housing retention.

Scatterplots of housing retention scores and fidelity are depicted in Figures 3 and 4. We calculated Spearman's rho correlations between fidelity scores and both measures of housing retention. HR1 was not significantly associated with fidelity $\left(r_{s}=.14, p=.32\right)$, and HR2 had a significant but weak correlation $\left(r_{s}=.33, p<.05\right)$.

There are two possible explanations for the lack of correlation between fidelity and HR1. As discussed above, programs operating using abstinence-based policies and procedures often have difficulty retaining hard-to-serve consumers. Therefore, the HR1 score might be inflated in $A B$ and $H F / A B$ programs due to the increased emphasis this measure places on consumers who are more stable (i.e., those who have been housed for 12 months or more). A second possible explanation is $\mathrm{AB}$ and $\mathrm{HF} / \mathrm{AB}$ programs are more likely to admit consumers they understand to be more stable and who are likely to be successful in their programs, a process known as "creaming" [43]. This is particularly true regarding the $A B$ programs that only accept consumers who have demonstrated the ability to remain abstinent for some time period. Contrasting this, HF programs do not have prerequisites for consumer admission. Because it results in differences in consumer populations across program types, creaming could lead one to conclude that the program, as opposed to traits of the consumer, is responsible for positive consumer outcomes.

In contrast, it is likely that we found a significant relationship between fidelity and HR2 because this puts less weight on consumer stability. That is, the measure takes into account that HF (and to some extent $\mathrm{HF} / \mathrm{AB}$ ) programs are more likely to take in higher risk individuals due to the presence of a lowthreshold admission policy. Indeed, it can be argued that the HR2 measure is more appropriate for understanding the relationship between fidelity and outcomes for this reason.

\section{Conclusions}

The development of the HFM Fidelity Index is an important step in ensuring the quality and consistency of HFM implementation. Our results demonstrate the index was generally valid and reliable. Arguably the most successful result is its ability to discriminate between the three different types of housing described. Overall, the results point to those elements related to harm reduction as being the most critical to the HFM. Despite this, a number of Housing First programs participating in the study had abstinence-based approaches to service provision that stood in direct conflict to a harm reduction approach. This confirms results from previous research that demonstrate how misunderstandings of the HFM result in programs having flexible admissions policies coupled with strict abstinence-based rules by which consumers must abide in order to keep their housing [7]. This is problematic considering the HFM was developed due to the difficulty "hard-to-serve" consumers have remaining permanently housed in programs with rules such as these [11].

Despite promising results, there are study limitations that need to be considered. Resource and time constraints prevented us from collecting data that would allow for the measurement of reliability beyond internal consistency (e.g., inter-rater, test-retest). Second, the Cronbach's alpha coefficient demonstrates that the index is reliable overall; however, there is need to further investigate the organization of the subdimensions based on the results. Third, our sample was relatively large for an organizational-level study; however, future studies with larger sample sizes would allow for additional analyses. Fourth, the findings might have been stronger had we eliminated elements with low item-total correlations from the instrument. We chose not to eliminate these elements because we see this study as a first step in the development of the instrument. Future work might justify their removal. Finally, the possibility of creaming (i.e., the tendency to recruit or admit only those consumers who are likely to be successful) within programs might be a confounding factor related to the housing retention measures. The inability to control for this issue demonstrates a limitation of the community-based research design; however, this is a reality of conducting research in naturalistic settings.

Despite the stated limitations, the HFM Fidelity Index does hold potential for researchers and practitioners. While we recognize one hundred percent fidelity is neither a goal nor a possibility for many organizations, the index offers a guide they can use to make implementation decisions and assess the quality of programming during the sustainability phase that follows implementation based on the level of fidelity they decide appropriate. The need for implementation guidelines has become 
even more important as the HFM is expanding beyond the United States [46]. Since we began our study, Pathways to Housing has also published an Essential Ingredients Checklist that should prove useful as an implementation guide [24]. However, Pathways has stated the checklist was designed to measure fidelity to the PHF model, and might not be appropriate for measuring fidelity in programs that have made adaptations, whether purposeful or accidental, to their model. Those programs specifically seeking to implement the PHF model should consult the Pathways fidelity checklist for guidance. Therefore, our index is likely to have greater flexibility when it comes to measuring the wide range of HFM programs that exist in practice. Finally, from a policy perspective, the index can be used by funders that support the HFM to help them assure their monies are being used in an appropriate fashion by programs that represent themselves as "Housing First."

Regarding next steps, we would like to investigate other approaches to establishing reliability of the index and its subdimensions. One of our primary goals is to collect a larger sample that will allow us to test the index using Item Response Theory and to compare those results to those obtained using classical test theory methods. This will assist in identifying those elements that are not truly representative of the underlying construct (i.e., the HFM), thus improving the instrument's validity [47]. We also plan to explore different approaches for identifying and organizing the subdimensions beyond face validity, which will potentially lead to stronger internal consistency.

\begin{abstract}
Abbreviations
$A B$ : Abstinence-based programs that were part of the study sample: HF: Housing First programs without abstinence-based principles that were part of the study sample; HF/AB: Housing First programs with abstinencebased principles that were part of the study sample; HFM: Housing First Model; HR1: A measure of housing retention calculated by dividing the total number of consumers who remained in the program for at least 12 months by the total number of consumers served during the contract year; HR2: A measure of housing retention calculated by dividing the total number of consumers who remained in the project during the contract year by the total number of consumers served during the contract year; HUD: U.S. Department of Housing and Urban Development; LTAP: Low-threshold admission policy; PHF: Pathways Housing First.
\end{abstract}

\section{Competing interests}

The authors have no competing interests to declare.

\section{Author's information}

DPW is Assistant Professor in the Richard M. Fairbanks School of Public Health and Faculty Research Associate at the Center for Health Policy at Indiana University-Purdue University Indianapolis.

JO is Assistant Professor in the School of Social Work at Loyola University Chicago. DW is Doctoral Candidate in the Department of Psychology at Loyola University Chicago.

VS, is the Associate Director of Heartland's Midwest Harm Reduction Institute in Chicago.

RT is Director of the Illinois Co-Occurring Center for Excellence at Heartland Health Outreach, Inc.

\section{Authors' contributions}

DPW was the primary investigator for the entire study participated in the drafting of the manuscript. JO participated in the study design and the drafting of the manuscript. DW was project manager and statistical analyst for the project and participated in the drafting of the manuscript. VS participated in the research design and analysis. RT provided significant input regarding the interpretation of the data as it related to practice. All authors read and approved the final manuscript.

\section{Acknowledgements}

Research funding provided by the National Institute on Drug Abuse (R36 DA027770).

\section{Author details}

${ }^{1}$ Department of Health Policy and Management, Indiana University, Richard M. Fairbanks School of Public Health, Indiana University-Purdue University Indianapolis, 714 N. Senate Ave, Indianapolis, IN 46202, USA. ${ }^{2}$ School of Social Work, Loyola University Chicago, 820 N. Michigan Ave, Chicago, IL 60611, USA. ${ }^{3}$ Department of Psychology, Loyola University Chicago, 1032 W. Sheridan Rd, Chicago, IL 60660, USA. ${ }^{4}$ Midwest Harm Reduction Institute, Heartland Health Outreach Inc, 1207 W. Leland Ave, Chicago, IL 6064, USA.

Received: 2 November 2012 Accepted: 29 April 2013

Published: 3 May 2013

\section{References}

1. Dickson-Gomez J, Convey M, Hilario H, Corbett AM, Weeks M: Unofficial policy: Access to housing, housing information and social services among homeless drug users in Hartford. Connecticut Subst Abuse Treat Prev Policy 2007, 2:8

2. Hopper K, Jost J, Hay T, Welber S, Haugland G: Homelessness, severe mental illness, and the institutional circuit. Psychiatr Serv 1997, 48:659-665.

3. Simpson DD, Joe GW, Broome KM, Hiller ML, Knight K, Rowan-Szal GA: Program diversity and treatment retention rates in the Drug Abuse Treatment Outcome Study (DATOS). Psychol Addict Behav 1997, 11:279-293.

4. National Alliance to End Homelessness: A plan, not a dream: How to end homelessness in ten years. Washington DC: National Alliance to End Homelessness; 2000.

5. U.S. Department of Housing and Urban Development: The 2009 annual homeless assessment report to Congress. Washington, D.C: Office of Community Planning and Development, HUD; 2010.

6. United States Interagency Council on Homelessness: Opening doors: Federal strategic plan to prevent and end homelessness: 2010 fact sheet. 2010.

7. George C, Chernega JN, Stawiski S, Figert A, Bendixen AV: Connecting fractured lives to a fragmented system: Chicago housing for health partnership. Equal Oppor Int 2008, 27:161-180.

8. Henwood BF, Stanhope V, Padgett DK: The role of housing: A comparison of front-line provider views in Housing First and traditional programs. Adm Policy Ment Health 2010, 38:77-85.

9. Pearson CL, Locke G, McDonald WR: The applicability of Housing First models to homeless persons with serious mental illness. Washington, D.C.: U.S: Department of Housing and Urban Development Office of Policy Development and Research; 2007.

10. Kuhn R, Culhane DP: Applying cluster analysis to test a typology of homelessness by pattern of shelter utilization: Results from the analysis of administrative data. Am J Community Psychol 1998, 26:207-232.

11. Tsemberis S, Asmussen S: From streets to homes - The Pathways to Housing Consumer Preference Supported Housing Model. Alcohol Treat Q 1999, 17:113-131.

12. Des Jarlais DC: Harm reduction-a framework for incorporating science into drug policy. Am J Public Health 1995, 85:10-12.

13. MacMaster SA: Harm reduction: a new perspective on substance abuse services. Soc Work 2004, 49:356-363.

14. Padgett DK, Stanhope V, Henwood BF, Stefancic A: Substance use outcomes among homeless clients with serious mental illness: Comparing Housing First with treatment first programs. Community Ment Health J 2010, 47:227-232.

15. Sadowski LS, Kee RA, VanderWeele TJ, Buchanan D: Effect of a housing and case management program on emergency department visits and hospitalizations among chronically ill homeless adults: A randomized trial. JAMA 2009, 301:1771-1778. 
16. Greenwood RM, Schaefer-McDaniel NJ, Winkel G, Tsemberis SJ: Decreasing psychiatric symptoms by increasing choice in services for adults with histories of homelessness. Am J Community Psychol 2005, 36:223-238.

17. Tsemberis S, Gulcur L, Nakae M: Housing first, consumer choice, and harm reduction for homeless individuals with a dual diagnosis. Am J Public Health 2004, 94:651-656.

18. DeSilva MB, Manworren J, Targonski P: Impact of a Housing First program on health utilization outcomes among chronically homeless persons. J Prim Care Community Health 2011, 2:16-20.

19. Mares AS, Rosenheck RA: Evaluation of the collaborative initiative to help end chronic homelessness. 2007.

20. Perlman J, Parvensky J: Denver Housing First Collaborative: Cost benefit analysis and program outcomes report. Denver, CO: Colorado Coalition for the Homeless; 2006.

21. National Alliance to End Homelessness: A shifting focus: What's new in community plans to end homelessness. Washington, D.C: National Alliance to End Homelessness; 2009.

22. Dusenbury L, Brannigan R, Falco M, Hansen WB: A review of research on fidelity of implementation: implications for drug abuse prevention in school settings. Health Educ Res 2003, 18:237-256.

23. Durlak JA, DuPre EP: Implementation matters: a review of research on the influence of implementation on program outcomes and the factors affecting implementation. Am J Community Psychol 2008, 41:327-350.

24. Tsemberis S: Housing First: The Pathways Model to End Homelessness for people with mental illness and addiction. Center City, MN: Hazelden; 2010.

25. Carroll C, Patterson M, Wood S, Booth A, Rick J, Balain S: A conceptual framework for implementation fidelity. Implement Sci 2007, 2:40.

26. Rieckmann T, Fuller BE, Saedi GA, McCarty D: Adoption of practice guidelines and assessment tools in substance abuse treatment. Subst Abuse Treat Prev Policy 2010, 5:4

27. Scanlon JW, Horst H, Nay JN, Schmidt RE, Waller AE: Evaluability assessment: Avoiding type III and IV errors. In Evaluation Management: A Source Book for Readings. Charlottesville, VA: U. S. Civil Service Commission; 1997:71-90.

28. Michie S, Fixsen D, Grimshaw JM, Eccles MP: Specifying and reporting complex behaviour change interventions: The need for a scientific method. Implement Sci 2009, 4:40.

29. Dane $\mathrm{AV}$, Schneider $\mathrm{BH}$ : Program integrity in primary and ealry secondary prevention: Are implementation effects out of control? Clin Psychol Rev 1998, 18:23-45.

30. Goodman RM: Bridging the gap in effective program implementation: From concept to application. J Community Psychol 2000, 28:309-321.

31. Orwin RG: Assessing program fidelity in substance abuse health services research. Addiction 2000, 95:309-327.

32. Neumiller S, Bennett-Clark F, Young MS, Dates B, Broner N, Leddy J, Kendall D, Richards S, De Jong F: Implementing assertive community treatment in diverse settings for people who are homeless with co-occurring mental and addictive disorders: A series of case studies. J Dual Diagn 2009, 5:239-263.

33. Matejkowski J, Draine J: Investigating the Impact of Housing First on ACT Fidelity. Community Ment Health J 2009, 45:6-11.

34. Damschroder LJ, Aron DC, Keith RE, Kirsh SR, Alexander JA, Lowery JC: Fostering implementation of health services research findings into practice: a consolidated framework for advancing implementation science. Implement Sci 2009, 4:50.

35. Century J, Rudnick M, Freeman C: A framework for measuring fidelity of implementation: A foundation for shared language and accumulation of knowledge. Am J Eval 2010, 31:199-218.

36. Nyden P, Hossfeld L, Nyden G: Public sociology: Research, action, change. Thousand Oaks, CA: Pine Forge Press; 2011.

37. McGrew JH, Bond GR: Critical ingredients of Assertive Community Treatment: Judgments of the experts. J Ment Health Adm 1995, 22:113-125.

38. McGrew JH, Bond GR, Dietzen L, Salyers M: Measuring the fidelity of implementation of a mental health program model. J Consult Clin Psychol 1994, 62:670-678.

39. Watson DP, Wagner DE, Rivers M: Understanding the critical ingredients for facilitating consumer change in Housing First programming: A case study approach. J Behav Health Serv Res 2013:1-11.

40. Eisenhardt KM, Graebner ME: Theory building from cases: Opportunities and challenges. Acad Mang J 2007, 50:25-32.
41. Patton MQ: Qualitative research and evaluation methods. Sage Publications; 2002.

42. U.S. Department of Housing and Urban Development: HUDHRE.info -- Grant Awards Search Results. http://www.hudhre.info/index.cfm?do=actionGrant AwardsSearch\&yr=2009\&rptType=CoC\&pickScope=all\&optTwo=\&optThree=]

43. Lipsky M: Street-level bureaucracy: Dilemmas of the individual in public service. Russell Sage Foundation; 2010.

44. Field A, Miles J: Discovering statistics using SAS. SAGE Publications; 2010.

45. DeVellis RF: Scale Development: Theory and Applications. 3rd edition. Thousand Oaks, CA: Sage; 2011.

46. Atherton I, Nicholls CM: "Housing First" as a means of addressing multiple needs and homelessness. European J Homelessness 2008, 2:289-303.

47. Wright $\mathrm{BD}$, Masters $\mathrm{GN}$ : Rating scale analysis. Rasch measurement. MESA Press; 1982.

doi:10.1186/1747-597X-8-16

Cite this article as: Watson et al:: The housing first model (HFM) fidelity index: designing and testing a tool for measuring integrity of housing programs that serve active substance users. Substance Abuse Treatment, Prevention, and Policy 2013 8:16.

\section{Submit your next manuscript to BioMed Central and take full advantage of:}

- Convenient online submission

- Thorough peer review

- No space constraints or color figure charges

- Immediate publication on acceptance

- Inclusion in PubMed, CAS, Scopus and Google Scholar

- Research which is freely available for redistribution 